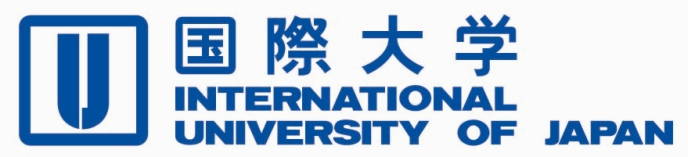

Economics \& Management Series

EMS-2011-14

\title{
Spatial Adaptation of the MSV Model, with Special Reference to World Development Report 2009 and Korean Examples
}

\author{
Jinhwan Oh \\ International University of Japan
}

July 2011

IUJ Research Institute

International University of Japan

These working papers are preliminary research documents published by the IUJ research institute. To facilitate prompt distribution, they have not been formally reviewed and edited. They are circulated in order to stimulate discussion and critical comment and may be revised. The views and interpretations expressed in these papers are those of the author(s). It is expected that the working papers will be published in some other form. 


\title{
Spatial Adaptation of the MSV Model, with Special Reference to World Development Report 2009 and Korean Examples
}

\begin{abstract}
Based on the spatially adapted Murphy, Shleifer, and Vishny (MSV) model, this paper reviews major concepts of the World Development Report 2009 - density, distance and division. It is argued that the concepts of poverty trap, and partial and complete industrialization in the model capture the stages of incipient (density), intermediate (distance), and advanced (division) urbanization, described in the report. In addition, the report explains the concepts of Critical Minimum Effort and the Critical Minimum Retreat through spatially blind, connective, and targeted policies, which are all appropriate policies for each stage of urbanization. Relevant Korean examples are provided.
\end{abstract}

Keywords Urbanization, Concentration, Congestion, Density, Distance, Division, Spatial Policies, Korea

JEL Classification O14, O18, R11, R12

\section{Introduction}

By theoretically employing the monopolistic competition model, it is easier to access and analyze geographical concentration and increasing returns, which have become ever more popular in the field of international trade, development economics, and economic geography.

For example, Krugman became a Nobel Laureate in 2008 for his contribution toward integrating international trade and economic geography. In addition, the World Development Report (WDR), the World Bank’s annual report, was entitled Reshaping Economic Geography in 2009 and focused on the geographical dimension of the development process as well as the role of cities and regions in improving the prosperity of under-developed and developing countries (Scott 2009). Moreover, Oh (2008) developed a model that provided a theoretical framework for explaining the possibility of an economy’s continuous existence in the supposed partial industrialization stage, where congestion costs exceed concentration benefits. This model is a spatial adaptation of the Murphy, Shleifer, Vishny (MSV) model that explains the concepts of 
poverty and industrialization as multiple Nash Equilibria and big push as a significant level of effort that propels an economy to the next stage.

Employing the model that was developed in Oh (2008), this paper reviews the WDR 2009, with special reference to Korean examples. The concepts of poverty, partial and full industrialization, and Critical Minimum Effort and Retreat will explain the key stages of incipient, intermediate, and advanced urbanization in an economy, as well as spatially blind, connective, and targeted policies.

This paper is organized as follows. Section 2 provides a brief description of the model, developed by Oh (2008). Section 3 reexamines the three major concepts of the WDR 2009 based on theoretical frameworks. Section 4 introduces relevant Korean examples, and Section 5 concludes the paper.

\section{Description of the model}

The most important feature of Oh's (2008) study is that it extended the MSV Model by adopting the concept of non-monotonicities in the technological externalities in a spatially agglomerated economy. The adoption of technological externalities to the MSV Model was initially introduced in Paternostro’s (1997) paper on dual externalities. He claimed that in an increasingly industrial economy, it is cheaper for one sector to become industrialized. In other words, the fixed cost $F$ decreases as the number of industrialized sectors $n$ increases, and thus, profit becomes an increasing function of $n$, thereby deriving multiple equilibria.

Oh (2008) argued that the number of firms not only influences the fixed cost $F$ but also the labor productivity $\alpha$. In other words, in an increasingly industrial economy, it is the cheaper and more productive for one sector to become industrialized, because $F$ decreases and $\alpha$ increases with an increase in the number of firms $n$. Moreover, his study states that, in the context of nonmonotonic externalities, there is a certain threshold of $n$ that separates concentration from overheated agglomeration as an economy becomes spatially agglomerated. As a result, $F$ and $\alpha$ tend to increase or decrease depending on whether or not the economy is over-concentrated, thereby allowing for non-monotonicities in the technological externalities.

Overall, by adding spatial issues to the MSV model, a modified version of the original model can be derived. Particularly, the profit $\pi$ of an entering high-tech firm (with increasing returns to 
scale technology as opposed to a low-tech fringe firm with constant returns to scale) is represented in the following manner:

$$
\pi=\frac{a(n) L-k F(n)}{k-n a(n)} \text { where }
$$

$a(n)=1-\frac{1}{\alpha(n)} ; \alpha=$ productivity; $L=$ the total number of workers; $k=$ the total number of sectors ; $n=$ the number of industrialized sectors; $F=$ fixed cost of each industrialized firm

Initial agglomeration yields a positive externality to the economy with reduced cost and improved productivity (knowledge spillover, etc.), in which $F$ decreases and $\alpha$ increases. However, once the number of firms exceeds a certain threshold, congestion becomes dominant, and, as a result, $F$ increases and $\alpha$ decreases. Therefore, profit will begin to decrease once the concentration benefits are exceeded by congestion costs, indicating the possibility of partial industrialization. In other words, unlike the original MSV model where industrialization gets off the ground when every firm participates in the market, an economy may get stuck in a state of partial industrialization.

However, this partial industrialization may not be the final destination of an economy. As indicated in Figure 1, even if an economy plunges into a zero-profit partial industrialization stage, it may recover if the external diseconomies of congestion disappear. For example, such an upturn can occur by expanding infrastructure networks. Subsequently, the threshold that distinguishes agglomeration from overconcentration shifts to the right. Simultaneously, external economies will dominate again, as a result of which $F$ decreases $\alpha$ increases with an increase in $n$. In this case, profits will begin increasing again in order to attain the state of full industrialization. Consequently, the economy observes three multiple and stable equilibria $a, b$, and $c$ that exhibit the poverty trap, partial industrialization, and full industrialization, respectively.

Additionally, Figure 1 explains Critical Minimum Effort (CME) and Critical Minimum Retreat (CMR). Initially argued by Leibenstein (1957), CME refers to the level of investment required by an underdeveloped country in order to escape from the vicious circle of poverty. In that light, Critical Minimum Effort may be interpreted as the smallest number of $n$, denoted by $n_{2}{ }^{*}$, such that once the number of industrialized sectors in an economy exceed $n_{2}{ }^{*}$, the other 
sectors industrialize on their own so that the economy is not getting caught in a state of partial industrialization. This partial industrialization is primarily attributable to issues of overconcentration and congestion. If these issues are resolved, the economy will attract investments from various industrialized sectors, which will eventually become equal to and exceed $n_{2}{ }^{*}$. On the other hand, CMR is a new concept, referring to the smallest number of $n$, denoted by $n_{1}{ }^{*}$, such that once the number of remaining industrialized sectors is less than $n_{1}{ }^{*}$, the others will leave the economy to avoid losses. When this occurs, the economy will collapse into the poverty trap with zero industrialization. This would occur if an economy is unable to solve its congestion problems and if external diseconomies of scale are too dominant to permit industrialized firms to sustain their businesses.

Figure 1. Partial \& Full Industrialization and Critical Minimum Effort \& Retreat

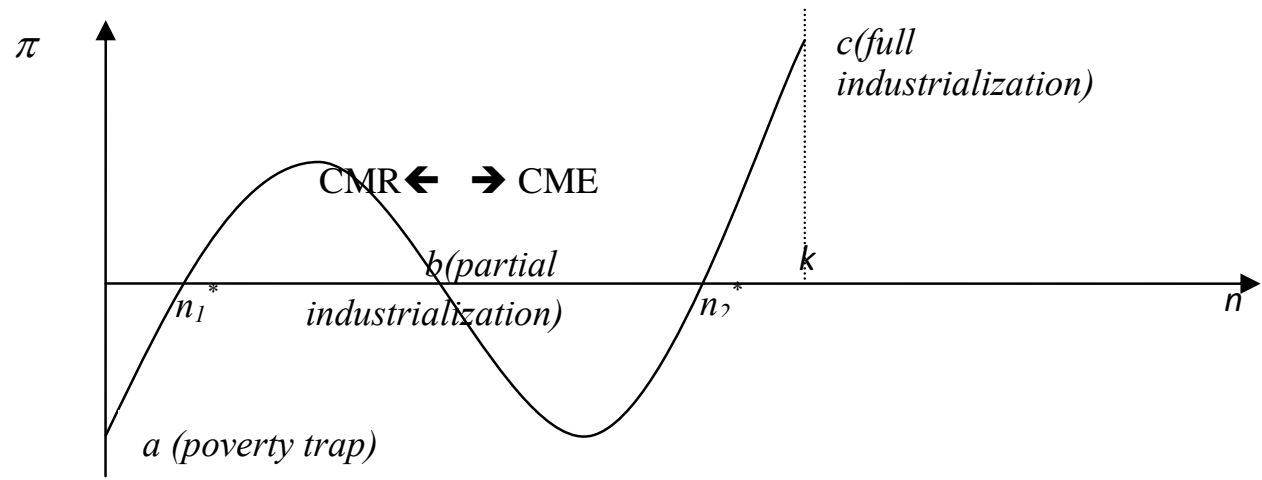

\section{Description of the WDR 2009 Using the Spatially Adapted MSV Model}

The World Bank's annual World Development Report (WDR) deals with specific topic of economic development annually. From a geographical perspective, the WDR 2009 charts the changes that accompany development in the following three spatial dimensions: rising density, falling distance, and persisting division. The report identifies the forces that influence the location of economic development. Subsequently, the report assesses public policies that may facilitate the spatial transformations necessary for sustaining economic growth and reducing geographic disparities in welfare. Drawing lessons from the experience of both developed and developing countries and recent advances in economic thinking, the WDR discusses promising approaches and interventions. 
Based on the stylized facts of urbanization and the discussion of agglomeration economies presented in Chapter 1 and Chapter 4, respectively, it is claimed that the overall objective of urbanization policies must be for building economic density in a manner that maximizes the potential benefits of agglomeration economies for society. In order to assist in the achievement of this objective, Chapter 7 of the report (“Concentration without Congestion: Managing and Integrated Portfolio of Places”), particularly describes a framework for urbanization policies in developing countries. This framework adopts an area-based approach, claiming that the appropriate spatial scale is an intermediate one, corresponding to sub-national areas, for example, the state or provincial level.

The framework distinguishes among the following three types of areas in developing countries: (1) incipient urbanization areas (less than 25 percent urban); (2) intermediate urbanization areas (between 25 and 75 percent urban); and (3) advanced urbanization areas (more than 75 percent urban). The policy challenge varies, depending on the type of areas. For incipient urbanization areas, the challenge is to build economic density; for intermediate urbanization areas, it is to build density and overcome problems of distance associated with congestion; and for advanced urbanization areas, it is to build density, overcome distance, and tackle economic and social division, caused by, for instance, the existence of slums within cities. Therefore, as the level of urbanization increases, the policy challenge escalate from being $1 D$ (density), to $2 D$ (density, distance), and further to $3 D$ (density, distance, division).

Correspondingly, different sets of instruments are required in order to tackle each of these different dimensions effectively. Spatially blind policy instruments of institution building are designed for building density, spatially connective instruments for overcoming problems of distance, and spatially targeted policies for economic and social divisions within cities.

Interestingly, concentration and congestion, as referenced in the report correspond to exiting the poverty trap and getting stuck in a partial industrialization stage, as examined in Oh (2008). Additionally, the concept of 1D (incipient urbanization), 2D (intermediate urbanization), and 3D (advanced urbanization) directly correspond to the concept of the three equilibria (poverty trap, partial industrialization, and full industrialization in my paper). Finally, appropriate policies (spatially blind, connective, and targeted) at each stage of urbanization may be explained through CME and CMR. That all being said, the spatial version of the extended MSV Model will operate as a theoretical framework for the WDR 2009.

Based on the spatial perspectives of the MSV model, incipient urbanization areas with 1D 
policies may correspond to an economy that has merely begun the big push and is exiting the poverty trap, i.e., point $a$ in Figure 1. With increasing agglomeration and urbanization, the economy will be centered around areas that are at the stage of intermediate urbanization areas, which can be referred to as point $b$ in the model, or the partially industrialized stage. Successful urbanization may be achieved following the provision and efficient management of spatially connective infrastructure in the transport sector, which can be referred to as CME. With the successful CME, the economy will eventually achieve advanced urbanization, or point $c$ (full industrialization); however, with a CMR, the economy may revert to $a$. Each stage requires effective policies in order to protect to the next stage, i.e., spatially blind policies for stage $a$, spatially connective policies for stage $b$, and spatially targeted policies for stage $c$.

Figure 2. The dimensions increase with the level of urbanization

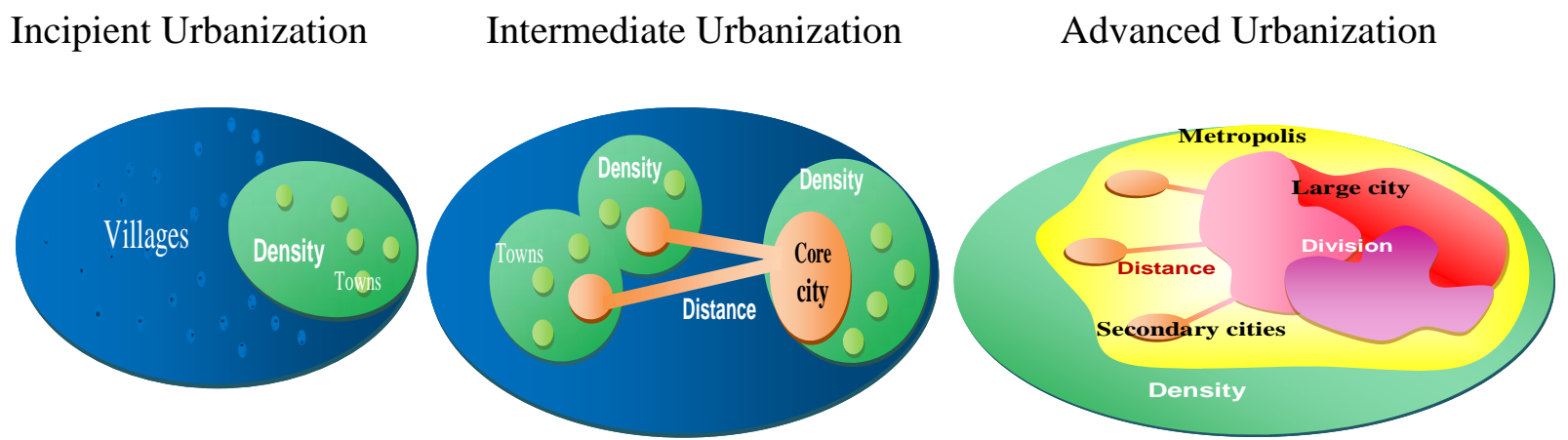

Source: World Development Report 2009

Table 1. Policy Reponses for Each Stage of Urbanization

\begin{tabular}{llll}
\hline & Incipient $(<25 \%)$ & Intermediate (25 75\%) & Advanced (>75\%) \\
\hline Required & Build Density (1D: & 1D+Reduce Distance (2D: & 1D+2D+Eliminate Inferior \\
& Spatially Blind) & Spatially Connective) & Division (3D: Spatially Targeted) \\
Examples & Institution Building & Infrastructure Provision & Slum Relocation \\
& & & \\
Goal & Unbalanced Growth, & Inclusive Development, & Integrated Development \\
& Agglomerations & No further congestion & \\
\hline
\end{tabular}




\section{Korean Examples}

Interestingly, the Republic of Korea possesses all the three policies and corresponding areas (the Eumseong County at the stage of incipient urbanization, Daegu metropolitan area at the stage of intermediate urbanization, and Seoul metropolitan area at the stage of advanced urbanization). Since the Seoul Metropolitan area has already been introduced in Oh (2008), this paper discusses the other two regions.

Figure 3. Korea: Three Areas at Different Stages of Urbanization

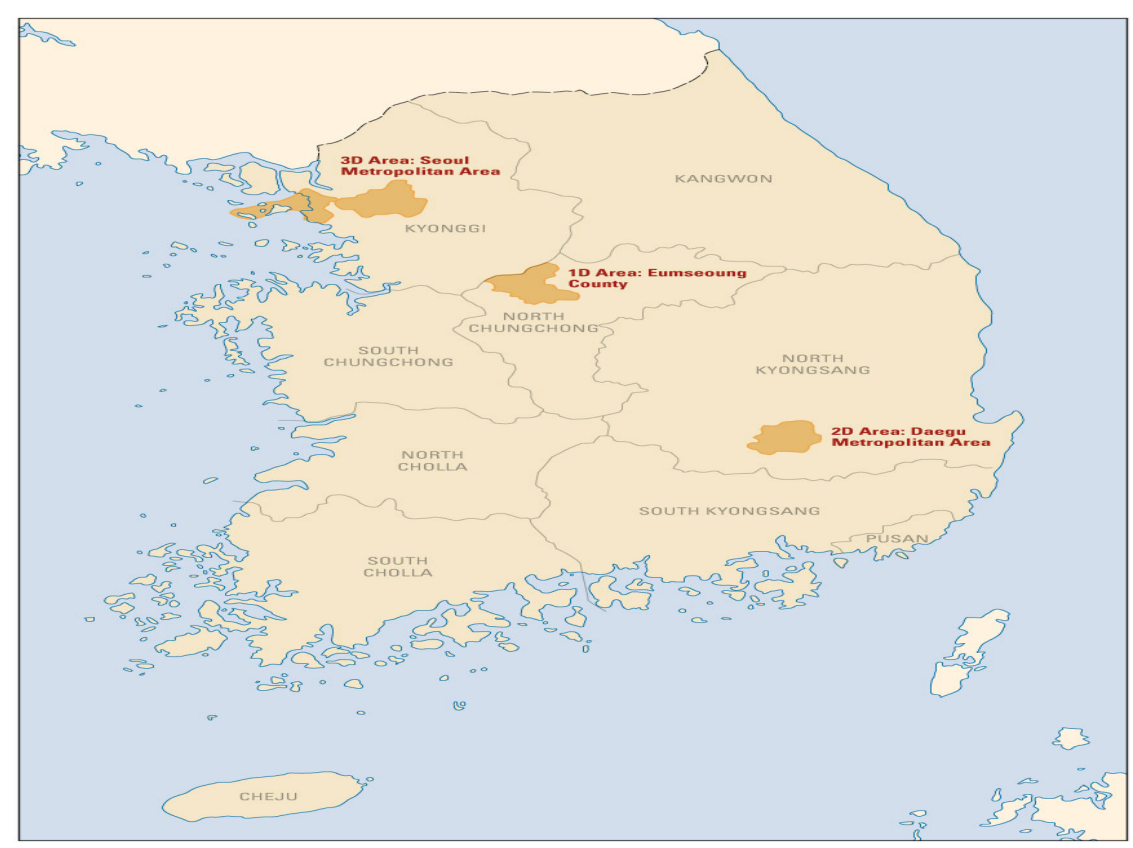

Source: World Development Report 2009

\subsection{Eumseong County}

For areas that are at the stage of incipient urbanization, policy priorities must be to provide basic social services and flexible land conversion for building regional density, which must be spatially blind, i.e., the policies must be effective throughout the region. Eumseong is a successful example in this regard. Employing the terms in the spatial MSV model, the region was able to exit point $a$ (Figure 1) and was prepared to enter the subsequent stage because of successful density building (1D) policies, including increasing the number of secondary schools and hospitals, as well as rate of water supply. 
In addition to basic social services, nationwide flexibility has been experienced with respect to land use conversion. Ever since Korea exited the agricultural society and entered the industrial era, it has required land for factories, buildings, and other institutions. Therefore, the government has been responsive with regard to converting agricultural into industrialized land. ${ }^{1}$ In certain cases, the government has enacted special laws and converted agricultural land into industrial complexes or expanded existing ones. Currently, there are 30 national industrial complexes throughout the country. In addition to these complexes, which are rather large and governed by the central government, local governments were encouraged by the central government for facilitating industrialization on the local level by creating small industrial complexes within these regions. In this regard, Eumseong County built several industrial complexes within its territory by converting a portion of its agricultural lands or forests into industrial lands. This conversion has been active since Korea adopted a decentralized administration system in 1995. In this new system, local people elect their mayors and local governments do not receive a budget from the central government. In order to finance itself, Eumseong attempted to host as many industries as possible by offering them space in the complexes.

Table 2. Industrial Complexes in Eumseong County

\begin{tabular}{llll}
\hline $\begin{array}{l}\text { Name of } \\
\text { Complex }\end{array}$ & $\begin{array}{l}\text { Number of } \\
\text { Companies }\end{array}$ & Major Products & Opened in \\
\hline Daepung & 7 & Machinery, chemicals, food & December 1996 \\
Daeso & 17 & Medical, chemicals, food & December 1996 \\
Soi & 4 & Machinery & December 1996 \\
Geumwang & 3 & Pulp, chemicals, food & June 2005 \\
Knit & 3 & Knit, clothes, textile & December 2000 \\
\hline
\end{tabular}

Source: Eumseong County Office

Note: Three other complexes (High-tech, Maengdong, and Gamgok) are currently under construction.

It must be noted that before Eumseong built these industrial complexes, the region had already measured up to its potential by establishing spatially blind institutions of basic social services despite lagging behind in terms of urbanization. Subsequently, opportunities for industrialization emerged - the region became a stopover along the Jungbu highway connecting Seoul and Daejeon (opened on December 3, 1987). Ever since, several companies in the Seoul Metropolitan Area began visiting Eumseong in order to draw benefit from the lower rents and

\footnotetext{
${ }^{1}$ In a majority of the cases, land use conversion is irreversible in the sense that once agricultural land is converted into industrialized land, it is very difficult to use it for agricultural purposes again.
} 
wages. Industrialization was further facilitated in the 1990s when Eumseong developed several industrial complexes in order to host additional firms and secure incremental revenue. As a result, Eumseong entered the stage of incipient industrialization. The number of the firms (including those in the industrial complexes) involved in production in the county rose to 89 in 2006, with a total of 3,021 employees and outputs worth 23,445 billon won (Table 3).

Table 3. Information on the Firms in Eumseong County

\begin{tabular}{llll}
\hline Year & $\begin{array}{l}\text { Number of } \\
\text { Companies }\end{array}$ & $\begin{array}{l}\text { Number of } \\
\text { Employees }\end{array}$ & $\begin{array}{l}\text { Gross Output } \\
\text { (in Billion Won) }\end{array}$ \\
\hline 2004 & 50 & 2,641 & 6,661 \\
2005 & 70 & 2,763 & 17,045 \\
2006 & 89 & 3,021 & 23,445 \\
\hline
\end{tabular}

Source: Eumseong County Office

Note: 1,000 Won $=\$ 1$ (approximately)

\subsection{Daegu Metropolitan Area}

Located in the southern part of the Korean peninsula, Daegu has been recognized for its leading textile industry since the early $20^{\text {th }}$ century, thereby resulting in the formation of a localization economy. In 1949, 16\% of Korea's entire textile industry was agglomerated in this city. Once Korea adopted export-oriented policies in the 1960s, the country exported those goods that had a competitive advantage, and the labor-intensive industry in this region, like the textile industry, developed further. This trend continued, and according to recent data, the textile industry in Daegu accounts for a significant proportion of its manufacturing industry.

Table 4. Total GDP, GDP of Manufacturing Industry (Mnfc), and Ratios: The Entire Country and Daegu Metropolitan City (Unit: 1 Million Won)

\begin{tabular}{|c|c|c|c|c|c|c|}
\hline & & 1985 & 1990 & 1995 & 2000 & 2005 \\
\hline \multirow{2}{*}{$\begin{array}{l}\text { Entire } \\
\text { Country }\end{array}$} & (A) GDP & $\begin{array}{l}87,975,945 \\
(200,387,140)\end{array}$ & $\begin{array}{l}194,546,006 \\
(332,274,083)\end{array}$ & $\begin{array}{l}410,130,587 \\
(485,493,634)\end{array}$ & $\begin{array}{l}577,970,942 \\
(577,970,942)\end{array}$ & $\begin{array}{l}817,811,875 \\
(730,121,176)\end{array}$ \\
\hline & $\begin{array}{l}\text { (B) GDP } \\
\text { Mnfc }\end{array}$ & $\begin{array}{l}20,634,007 \\
(49,512,372)\end{array}$ & $\begin{array}{l}46,903,715 \\
(85,747,529)\end{array}$ & $\begin{array}{l}101,129,961 \\
(114,111,207)\end{array}$ & $\begin{array}{l}149,486,779 \\
(149,486,779)\end{array}$ & $\begin{array}{l}207,991,085 \\
(202,550,689)\end{array}$ \\
\hline Ratio & $\mathrm{B} * 100 / \mathrm{A}$ & $\begin{array}{l}23.5 \% \\
(24.7 \%)\end{array}$ & $\begin{array}{l}24.1 \% \\
(25.8 \%)\end{array}$ & $\begin{array}{l}24.7 \% \\
(23.5 \%)\end{array}$ & $\begin{array}{l}25.9 \% \\
(25.9 \%)\end{array}$ & $\begin{array}{l}25.4 \% \\
(27.7 \%)\end{array}$ \\
\hline Daegu & (C) GDP & $\begin{array}{l}3,820,239 \\
(8,779,457)\end{array}$ & $\begin{array}{l}8,538,675 \\
(14,537,975)\end{array}$ & $\begin{array}{l}15,782,226 \\
(20,364,899)\end{array}$ & $\begin{array}{l}20,776,260 \\
(20,776,260)\end{array}$ & $\begin{array}{l}26,729,159 \\
(23,000,935)\end{array}$ \\
\hline
\end{tabular}




\begin{tabular}{|c|c|c|c|c|c|c|}
\hline & $\begin{array}{l}\text { (D) GDP } \\
\text { Mnfc }\end{array}$ & $\begin{array}{l}1,481,354 \\
(3,186,650)\end{array}$ & $\begin{array}{l}2,918,722 \\
(4,662,631)\end{array}$ & $\begin{array}{l}4,134,080 \\
(6,164,399)\end{array}$ & $\begin{array}{l}4,863,290 \\
(4,863,290)\end{array}$ & $\begin{array}{l}5,311,466 \\
(4,846,997)\end{array}$ \\
\hline Ratio & D*100/C & $\begin{array}{l}38.8 \% \\
(36.3 \%)\end{array}$ & $\begin{array}{l}34.2 \% \\
(32.1 \%)\end{array}$ & $\begin{array}{l}26.2 \% \\
(30.3 \%)\end{array}$ & $\begin{array}{l}23.4 \% \\
(23.4 \%)\end{array}$ & $\begin{array}{l}19.9 \% \\
(21.1 \%)\end{array}$ \\
\hline
\end{tabular}

Source: Korea Statistical Information Service (KOSIS), National Statistical Office of the Republic of Korea \& Daegu Metropolitan City.

Note: 1 Million Won = \$971 (as on May 30, 2008). The non-parentheses data indicates current prices, and those within parentheses indicate constant prices at 2000.

Table 5. The Number of Companies, Employees, and Ratios: The Entire Manufacturing (Mnfc) Industry and Textile Industry of Daegu Metropolitan City (Unit: Number)

\begin{tabular}{llllllll}
\hline & & 2001 & 2002 & 2003 & 2004 & 2005 & 2006 \\
\hline Entire & (A) Companies & 6,707 & 7,050 & 6,921 & 7,068 & 6,921 & 6,735 \\
Mnfc & (B) Employees & 126,478 & 128,961 & 124,886 & 124,439 & 121,698 & 122,594 \\
Industry & (C) Companies & 2,439 & 2,465 & 2,273 & 2,126 & 1,984 & 1,868 \\
Daegu & & & & & \\
Textile & (D) Employees & 48,517 & 46,705 & 41,465 & 36,446 & 31,094 & 28,748 \\
Industry & (C)*100/(A) & $36 \%$ & $35 \%$ & $32.8 \%$ & $30.1 \%$ & $28.7 \%$ & $27.7 \%$ \\
Ratio & (D)*100/(B) & $38.4 \%$ & $36.2 \%$ & $33.2 \%$ & $29.3 \%$ & $25.6 \%$ & $23.4 \%$ \\
\hline
\end{tabular}

Source: Korea Statistical Information Service (KOSIS), National Statistical Office of the Republic of Korea \& Daegu Metropolitan City

Note: The original data divided the textiles sector into three categories (textiles except sewn wearing apparel, sewn wearing apparel and fur articles, and tanning and dressing of leather). For simplicity, this paper combines these three categories.

Similar to other cities in Korea, Daegu was once at an incipient stage of urban development. As stated in the WDR 2009, "spatially blind policies” are required at the stage of incipient urbanization in order to exit the poverty trap, denoted as point $a$ in Oh's (2008) model. Various sources of data indicate that Daegu had concrete policies that contributed to its density building. For example, education investments in the region have gradually increased and the number of students per teacher have steadily decreased at all levels including elementary, middle, and high school, which implies that the quality of public education has improved over the past three decades. In addition, there have been improvements in the health care system. The number of hospitals per million people in the Daegu area has been increasing since 1981. Moreover, the rate of water supply has been maintained at over 90\% since 1980 (Daegu Metropolitan Government). All these examples imply that basic nationwide social service policies improved the social welfare and contributed to the density building of the city. 
Additionally, Oh’s (2008) model predicts that economies that successfully launched industrialization projects may stagnate if a congestion effect dominates the external economies of scale. The city of Daegu serves as a good example in this regard. Daegu is an inland city, surrounded by high mountains: Mt. Palgongsan in the north, Mt. Daedeoksan and Mt. Biseulsan in the south, and other low mountains in the west and east, all of which present natural land constraints (Daegu Metropolitan City). Moreover, Daegu's localization economy focused on a labor-intensive textile industry, which facilitated migration from other areas. As a result, when Daegu entered the stage of intermediate urbanization (2D), it suffered from issues of congestion, especially in the late 1980s, such as soaring number of vehicles from 100,000 in 1998 to 600,000 in 1998 and land price increase by more than 50\% (KOSIS).

For areas that are at the stage of intermediate urbanization, policy priorities must be not only to provide basic social services but also to provide spatially connective policies, which may correspond to the CME in Figure 1 and which may function as a momentum to escape from the point $b$ (partial industrialization). The city of Daegu serves as a suitable example of these policies. In order to prevent potential congestion problems, Daegu expanded its territory by including neighboring regions in its administrative zone. Until 1987, Daegu's area was 396.4 $\mathrm{km}^{2}$. By 1988, it included the area currently known as Dalseo-gu $\left(62.26 \mathrm{~km}^{2}\right)$, and in 1995, it absorbed another area currently known as Dalseong-gun $\left(427.04 \mathrm{~km}^{2}\right)$, which is approximately as large as the former Daegu area (now Daegu Metropolitan City).

Immediately following its expansion, the city constructed two metro lines in order to connect different locations within the Greater Daegu region. A portion of Line 1 that connected Jincheon to Joongangro, first opened in 1997, and the remaining portion of the line, which traversed north to south was opened in 2001. Line 2, which was opened in 2005, traversed east to west. Additional lines have been planned. Moreover, the city expanded its existing bus route to 104 lines, effectively connecting the entire city (Daegu Metropolitan City).

Furthermore, the city established a new public transportation system in February 2006, combining the existing subway and bus lines under one network. This network connected the bus lines to the subway more efficiently, increased the bus routes by a distance of $26 \mathrm{~km}$, and the speed of buses from $17.7 \mathrm{kmph}$ to $22.4 \mathrm{kmph}$ (Daegu Metropolitan City). The city expected to benefit from the new public transportation system in terms of a rise in the number of people using public transportation from 870 thousand to 1 million per day, thereby reducing the use of 
private automobiles. Additionally, the quality of roads in the Daegu area has been superior since the 1980s. For example, the road pavement rate in Daegu continued to rise over the last three decades and hit $99 \%$ in 2005 , which exceeds the average national rate (77\%) by a significant margin (Daegu Metropolitan Government).

In addition to intra-regional connectivity, inter-regional connective policies are rather active. Ever since the first highway connecting Seoul and Busan via Daegu was built in 1970; six highways connecting the Daegu area to other parts of Korea have been constructed (Table 6). Currently, three new highways are under construction.

Table 6. Highways in Korea Connecting Daegu Area

\begin{tabular}{llll}
\hline Name & Route & Length & Opened in \\
\hline Gyeongbu & Seoul-Busan (via Daegu) & $428 \mathrm{~km}$ & July 07, 1970 \\
Guma & Daegu-Masan & $82.4 \mathrm{~km}$ & December 17, 1977 \\
Olympic & Daegu-Gwangju & $175.3 \mathrm{~km}$ & June 27, 1984 \\
Joongang & Daegu-Chuncheon & $280 \mathrm{~km}$ & December 19, 2001 \\
DaeguPohang & Daegu-Pohang & $68.4 \mathrm{~km}$ & December 07, 2004 \\
DaeguBusan & Daegu-Busan & $82 \mathrm{~km}$ & January 25, 2006 \\
\hline
\end{tabular}

Source: Korea Expressway Corporation

Furthermore, Daegu has dense railroad networks connecting other areas. Railroads had been constructed in the distant past, for example, the Gyeongbu Line, connecting Seoul and Busan via Daegu was built as early as 1905. Nearly a hundred years later, Korea experienced the second round of railway development when it launched the Korea Train Express (KTX) in 2004, a new bullet train system. With this system, it takes under 2 hours to travel from Daegu to Seoul, and under 1 hour from Daegu to Busan.

The first benefit of spatially connective policies is decentralization. According to Table 7, Daegu’s GDP in the manufacturing sectors has been declining since 1995 ( $\$ 6.16$ billion in 1995, $\$ 4.86$ billion in 2000, and \$4.84billion in 2005; approximate values with constant prices at 2000). As such, the ratio of the GDP in the manufacturing sectors to whole sectors declined from $30.3 \%$ to $21.3 \%$. On the other hand, as indicated in Table 7, the GDP in the manufacturing sectors increased in the neighboring Gyeongsangbukdo Province (both in terms of numbers and ratio), confirming the decentralization of manufacturing sectors in the neighboring provinces. 
Table 7. Total GDP, GDP of Manufacturing Industry (Mnfc), and Ratios: Gyeongsangbukdo Province (Unit: 1 Million Won)

\begin{tabular}{|c|c|c|c|c|c|c|}
\hline & & 1985 & 1990 & 1995 & 2000 & 2005 \\
\hline \multirow{6}{*}{$\begin{array}{l}\text { Gyeong- } \\
\text { sang- } \\
\text { bukdo- } \\
\text { province }\end{array}$} & & $6,724,417$ & $13,504,039$ & $25,931,314$ & $38,445,650$ & $57,748,323$ \\
\hline & & $(14,484,061)$ & $(21,728,029)$ & $(29,586,021)$ & $(38,445,650)$ & $(53,902,299)$ \\
\hline & (B) GDP & $1,995,229$ & $4,421,841$ & $8,404,880$ & $15,234,580$ & 25,224,662 \\
\hline & Mnfc & $(4,912,593)$ & $(8,056,046)$ & $(9,772,293)$ & $(15,234,580)$ & $(24,336,349)$ \\
\hline & Ratio & $30 \%$ & $33 \%$ & $32 \%$ & $40 \%$ & $44 \%$ \\
\hline & $(B) * 100 /(A)$ & (34\%) & (37\%) & (33\%) & $(40 \%)$ & $(45 \%)$ \\
\hline
\end{tabular}

Source: Korea Statistical Information Service (KOSIS), National Statistical Office of the Republic of Korea

Note: 1 Million Won = \$971 (as on May 30, 2008). The Non-parentheses numbers indicate current prices, and those within parentheses indicate constant prices at 2000.

An interesting phenomenon is that certain regions lay greater emphasis on particular sectors during the process of decentralization, forming localization economies in a broader sense; there are five cities around Daegu with direct access to the highway and KTX. The closest city to Daegu is Gumi, ${ }^{2}$ which is located 33 km north of Daegu. Gumi has the largest inland industrial complex in Korea, with 786 companies and 74,039 employees (out of a total population of 386,465). Like in Daegu, Gumi's major industry was textiles; however, currently, only 3\% of the companies in Gumi belong to the textile sector, whereas 84\% of the companies belong to the electronic sector. Gumi is known as "Korea’s Silicon Valley,” owing to the increasing number of companies in the electronic sector. Particularly, a majority of the Samsung mobile phones and LG liquid crystal display (LCD) television monitors are produced in Gumi for domestic consumption as well as for export purposes. To the east of Daegu, there are three coastal cities: Pohang, Ulsan, and Busan. Pohang is located $70 \mathrm{~km}$ east of Daegu. It houses POSCO (Pohang Steel Company), one of the largest steel producers in the world, producing 31 million tons of steel annually. The Hyundai manufacturing facility for automobiles and its dockyard are located

\footnotetext{
${ }^{2}$ Gumi is the hometown of the former president Park Chung-hee. The industrial complex in Gumi was opened in 1968.
} 
at the city of Ulsan, which produces approximately 2 million cars and $13 \%$ of the world's ships annually. $^{3}$

\section{Figure 4. Decentralization and Localization Economies around Daegu Area}

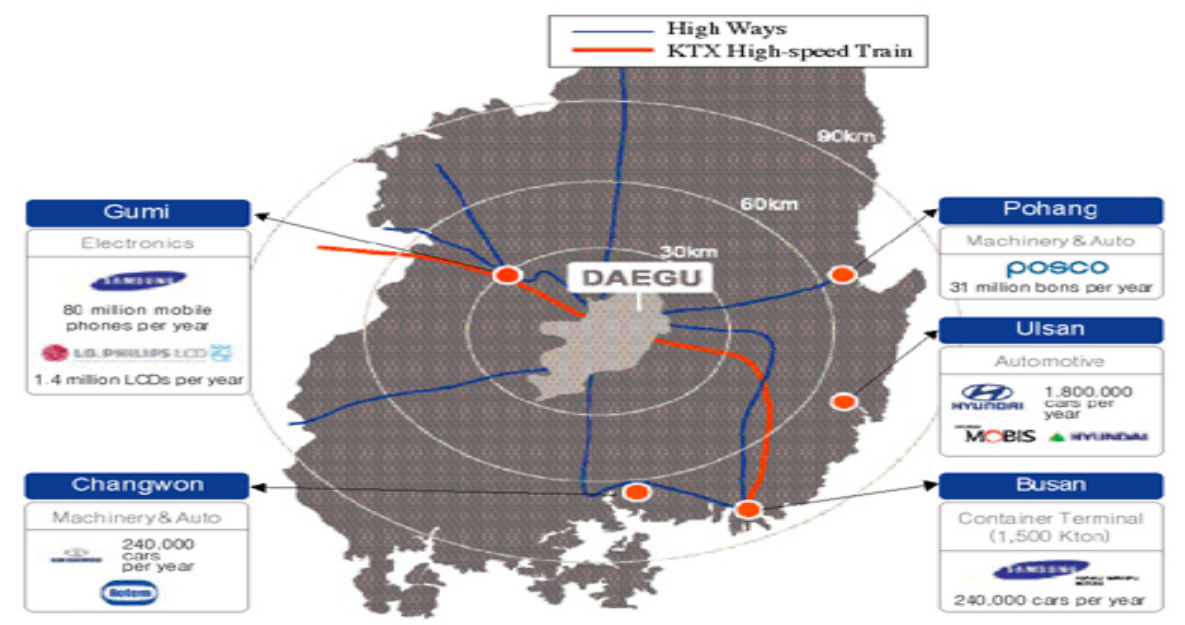

Source: Daegu Metropolitan Government

Simultaneously, the industrial structure within Daegu is becoming increasingly diversified. Table 8 indicates that the ratio of the textile industry to other industries has been gradually declining. The ratio of the number of companies in the textile industry to other industries declined from 36\% in 2001 to $21.7 \%$ in 2006 and the ratio of the number employees from 38.4\% in 2001 to 23.4\% in 2006. Nevertheless, the total number of employees in Daegu's nine industrial complexes increased from 85,763 in 2001 to 122,594 in 2006. In other words, even though the industry in general expanded in the Daegu region, the size of the textile industry diminished. In fact, other industries are attempting to close this gap. According to Table 8, out of total of 6,735 manufacturing enterprises, $43 \%$ are in the machinery sector (including metal engineering and auto parts), exceeding the number of companies in the textile sector by $16 \%$ (Korea Industrial Complex Organization).

\footnotetext{
${ }^{3}$ Through their significant contributions in terms of the export of manufactured goods, Pohang and Ulsan have served as the engines of Korea’s economic growth. In the process of “learning by doing," human capital has accumulated, which has improved productivity. According to Lucas (1993), this improved productivity has fueled Korea's rapid economic growth. According to Lucas, Korea’s "growth miracles” are based on "productivity miracles.”
} 
Table 8. Manufacturing Industries in Daegu (2006)

\begin{tabular}{lll}
\hline Sector & Number of Companies (Rate) & Number of Employees (Rate) \\
\hline Total & 6,735 & 122,594 \\
Machinery & $2,948(43 \%)$ & $46,515(38 \%)$ \\
Textile & $1,848(27 \%)$ & $28,599(23 \%)$ \\
Automobile & $319(5 \%)$ & $13,842(11 \%)$ \\
Electronics & $102(2 \%)$ & $8,952(7 \%)$ \\
Others & $1,518(23 \%)$ & $24,686(21 \%)$ \\
\hline
\end{tabular}

Source: Daegu Metropolitan Government

Although there is diversification within the city in terms of the presence of various industrial sectors, the city is becoming localized with respect to industrial complexes. For example, almost all the companies in the Jesam-gongdan industrial complex are in the machinery sector and the Daegu Dying complex, as its name indicates, is entirely occupied by textile companies.

Table 9. Industrial Complexes in Daegu

\begin{tabular}{lllllll}
\hline Name & Machinery & Textile & Automobile & Electronics & Others & Total \\
\hline Seongseo & 2,858 & 1,206 & 524 & 258 & 982 & 5,828 \\
Dalseong & 1,065 & 545 & 361 & 167 & 287 & 2,425 \\
Jesam-gongdan & 1,230 & 47 & 0 & 29 & 91 & 1397 \\
SeoDaegu-gongdan & 206 & 343 & 20 & 0 & 303 & 2417 \\
Daegu Dyeing & 0 & 123 & 0 & 0 & 1 & 124 \\
Geomdan & 87 & 40 & 57 & 49 & 153 & 386 \\
Okpo & 5 & 13 & 0 & 2 & 20 & 40 \\
Guji & 6 & 4 & 0 & 2 & 12 & 24 \\
Hyeonpung & 2 & 0 & 0 & 0 & 5 & 7 \\
\hline
\end{tabular}

Source: Daegu Metropolitan City

Overall, the textile industry is evolving. Daegu Metropolitan City launched the supposed Milano Project for nurturing the textile business in this area in order to make them increasingly competitive in the global market. Six-hundred eighty billion won will be invested in this project, which will attempt to transform the structure of Daegu's textile business from a low-skilled labor intensive to a high value added industry and lay more emphasis on fashion design research.

\section{Conclusion}

Scott (2009) criticized the WDR 2009 on the pretext that it lacks theoretical foundations and results in a "superficial treatment" of economic geography and development policy. Against this 
backdrop, this paper revisits the report with the spatially modified MSV Model. In particular, Chapter 7 of the report deals with the issues of concentration and congestion and examines policies for inclusive urbanization, which may have been well captured by the aforementioned spatial version of the MSV model. Moreover, urbanization processes in Eumseong County and Daegu Metropolitan Government in Korea work as supporting examples for this model, coupled with the example of Seoul Metropolitan Government described in Oh (2008).

For urban and development policies to be successful, space must be taken into consideration. In other words, "spatially connective” policies must follow density building in order to reduce distance, and "spatially targeted" policies must follow spatially connective policies in order to resolve division problems. In the absence of effective connective policies, initial concentration will only focus on congestion. In the absence of effective targeted policies, a region cannot be integrated. A combination of $1 \mathrm{D}, 2 \mathrm{D}$, and 3D policies is required in order to achieve economic growth and, eventually, a comprehensive integration of an economy. 


\section{References}

Daegu Metropolitan City: http://english.daegu.go.kr

Eumseong County Office: http://english.es21.net

Korea Expressway Corporation: http://www.ex.co.kr/english

Korea Statistical Information Service: http://www.kosis.kr

Krugman, P.R.: Development, Geography, and Economic Theory. The MIT Press, Cambridge, MA (1997)

Krugman, P.R.: The Role of Geography in Development. Annual World Bank Conference of Development Economics. World Bank (1998)

Leibenstein, H.: Economic Backwardness and Economic Growth. Wiley, New York (1957)

Murphy, K.M., Shleifer, A., Vishny, R.: Industrialization and the Big Push. Journal of Political Economy. 97, 1003-1026 (1989)

Oh, J.: Congestion, Concentration, and the Dynamics: Spatial Remodeling of the Murphy, Shleifer, and Vishny Model. Letters in Spatial and Resource Sciences (2008)

Paternostro, S.: The Poverty Trap: The Dual Externality Model and Its Policy Implications. World Development, 25: 2071-2081 (1997)

Rigg, J., Bebbington, A., Gough, K. V., Bryceson, D. F. Ageraard, J., Fold, N., \& Tacoli, C.The World Development Report 2009 Reshapes Economic Geography: Geographical Reflections.

Transactions of the Institute of British Geography, 34: 128-136 (2009)

Scott, A. Book Review. The World Development Report 2009. Journal of EconomicGeography. (2009)

WDR (2009). World Development Report 2009; Reshaping Economic Geography. World Bank 